\title{
PALEOPATHOLOGICAL FINDINGS OF DRY SKULLS WITH PLAGIOCEPHALY
}

\author{
Blanka Pospísilová, Olga Procházková \\ Charles University in Prague, Faculty of Medicine in Hradec Králové, Czech Republic: Department of Anatomy
}

\begin{abstract}
Summary: In literature, plagiocephaly is defined as abnormal asymmetrical head shape with unilateral flattening of the anterior and/or posterior part of the skull. It is classified as synostotic or deformational. Synostotic plagiocephaly is the result of premature unilateral fusion of neurocranim sutures. Positional plagiocephaly is caused by asymmetrical intrauterine and/or postnatal external forces. The authors report findings of both types of plagiocephaly in the dry skull collection from pertaining Broumov Ossuary ( $13^{\text {th }}-18^{\text {th }}$ century), Czech Republic. In the paper, the incidence of paleopathological asymmetrical skull deformities is discussed in the context with recent clinical data.
\end{abstract}

Key words: Plagiocephaly; Craniosynostosis; Synostotic plagiocephaly; Unicoronal synostosis; Unilambdoid synostosis; Deformational plagiocephaly; Paleopathology

\section{Introduction}

Plagiocephaly is a general term for abnormal asymmetrical cranium shape with unilateral flattening of the anterior or posterior part of the skull. The term meaning "oblique head" ("lopsided skull”) derives from the Greek word roots "plagios" and "kefalê". Pathogenically, plagiocephaly can be classified as synostotic (organic) or deformational (positional, functional, postural, nonsynostotic) (21). Synostotic plagiocephaly is caused by premature unilateral fusion of the coronal suture (frontal or anterior synostotic plagiocephaly), lambdoid suture (occipital or posterior synostotic plagiocephaly, true occipital plagiocephaly) or lateral skull sutures $(1,4,17,21)$. In the literature, the term "hemicranial plagiocephaly" is sometimes used for deformities associated with multiple unilateral sutural fusions (1). Deformational occipital (posterior) plagiocephaly is caused by intrauterine and/or postnatal external forces on the one side parietooccipital region of the developing skull (13).

Morphological characteristics of the frontal plagiocephaly (Figs. 1, 2) are following $(5,10,18,19)$ : asymmetrical "rhombdoid" skull shape (in vertex view), asymmetry of the skull base (predominantly of the anterior cranial fossa), ipsilateral flattening of the forehead and ipsilateral compensatory occipital bossing, contralateral compensatory bossing of the forehead (asymmetrical "pointed" forehead), asymmetry of the nose root (it is deviated towards fused coronal suture), asymmetry of the orbits (ipsilateral orbit is enlarged and elevated), and asymmetrical position of the ears (the ear of the affected side is situated anterior and superior). Three forms of frontal plagiocephaly are defined: mild form (with minimal frontal flattening, symmetrical orbits, and a midline nose), moderate form (with ipsilateral flattening, compensatory contralateral bossing, and nasal root deviation), and severe form (with vertical orbital dystopia, severe ipsilateral flattening, contralateral bossing, and deviation of the nose root) (19). Occipital synostotic plagiocephaly (Fig. 1 ) is characterized by the asymmetrical "trapezoid" skull shape (in vertex view), ipsilateral flattening of the forehead and bulging of the mastoid process (it is pathognomotic for unilambdoid synostose), compensatory contralateral bossing of the forehead and occiput: "pointed" occiput, asymmetry of the ears (ipsilateral ear is situated posterior); facial asymmetry is not mostly severe $(12,16,21)$. Occipital positional plagiocephaly (Fig. 2) is associated with asymmetrical "parallelogram" skull shape, unilateral parieto-occipital flattening, ipsilateral frontal bossing, contralateral frontal flattening and occipital bossing, asymmetry of external nose (nasal root is in a midline position but nasal bones and piriform aperture are deviated on the contralateral side), asymmetry of the orbits (contralateral orbit is situated low then ipsilateral orbit), asymmetry of the ear position (ipsilateral ear is situated anterior and superior) $(9,11,13,16,21)$. Positional plagiocephaly can be classified as mild (without facial asymmetry) or severe (with facial asymmetry) (3).

\section{Material and Methods}

The incidence of the synostotic and/or deformational plagiocephaly was investigated in the collection of 745 dry skulls (647 skulls of adults of both sexes, 98 skulls of children) from "Broumov Ossuary" $\left(13^{\text {th }}-18^{\text {th }}\right.$ century $)$, Czech 
Republic. All skulls were minutely investigated by cranioscopy and craniometry. Positive findings of plagiocephaly were documented by the digital camera Camedia 3030 ZOOM, Olympus. In the part of them, X-ray and/or computed tomography (CT) examination was performed.
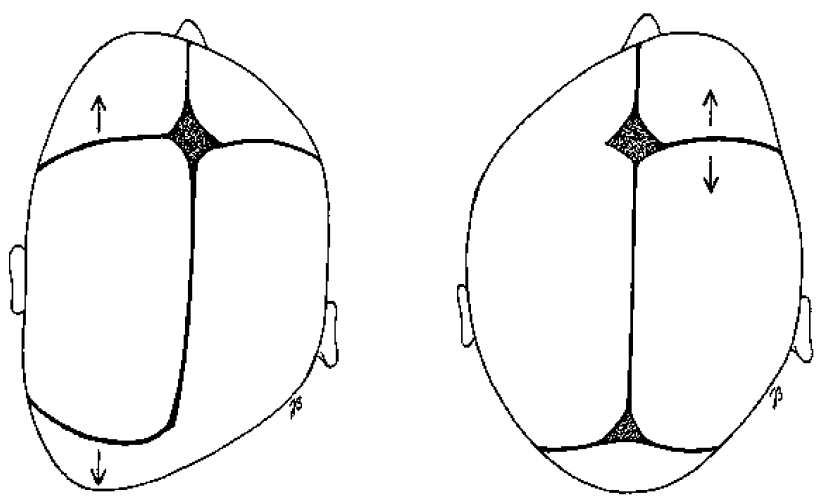

Fig. 1: Schematic picture of the skull shape deformities in the occipital (A) and frontal (B) synostotic plagiocephaly; arrows: compensational growth of the cranium.
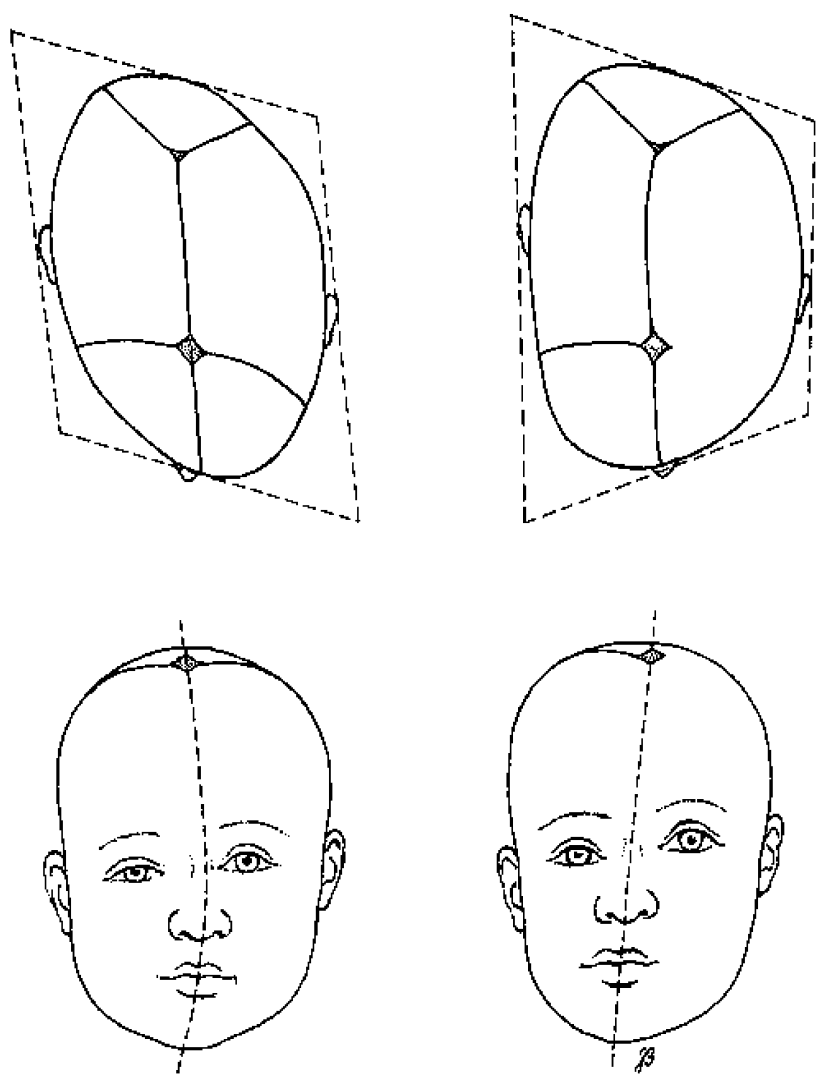

Fig. 2: Schematic drawing of morphological characterizations of the occipital positional plagiocephaly (A) and frontal synostotic plagiocephaly (B). Upper: skull shape (vertex view), lower: face asymmetry.

\section{Results}

Of the 745 examined dry skulls, 106 skulls (14.22\% 87 adult skulls, 19 children's skulls) had evidence of plagiocephaly. From the total number of skulls, synostotic plagiocephaly (Figs. $3-7)$ was noticed in 13 (1.74\%) skulls (8 adult skulls, 5 children's skulls), occipital deformational plagiocephaly (Figs. 8-10) in 93 (12.48\%) skulls (79 adult skulls, 14 children's skulls). Frontal synostotic plagiocephaly with unicoronal fusion was seen in $2(0.27 \%)$ skulls ( 1 adult skull, 1 child's skull) (Fig. 3, 4). Occipital unilambdoid synostotic plagiocephaly was diagnosed in $1(0.13 \%)$ skull of adult individual. Synostotic plagiocephaly caused by asymmetrical obliterations of some skull sutures was observed in 7 (0.94\%) skulls (5 adult skulls, 2 children's skulls) (Fig. 5). Premature fusions of multiple cranium sutures associated with synostotic plagiocephaly and another form of synostotic skull deformity (scaphocephaly or brachycephaly) was found in $3(0.40 \%)$ skulls ( 1 adult skull, 2 children's skulls) (Figs. 6, 7).

\section{Discussion}

Presented paleopathological study is focused on the incidence of synostotic and/or deformational plagiocephaly in the dry skull collection from the Broumov Ossuary $\left(13^{\text {th }}-18^{\text {th }}\right.$ century), Czech Republic. Although asymmetrical skull deformities are quite common today, not many cases have been described in the paleopathological literature (1).

In the literature, the craniosynostosis is defined as a premature fusion of one or more of cranial sutures (8). It can occur as an isolated defect (nonsyndromic) or as a part of the syndrome (e.g. Crouzon, Apert, Pfeifer, Cole-Carpenter). It may affect the coronal, sagittal, metopic, lambdoid and/or lateral sutures in isolation or in combinations (14). The skull growth is restricted predominantly in a direction perpendicular to the premature fused suture. In response to the closed suture, the remaining sutures undergo compensatory growth. Uncorected craniosynostosis may be associated with deformity of the craniofacial skeleton and it can also cause serious constriction of the developing brain (craniostenosis), eyes (orbitostenosis), and facial viscera (faciostenosis) (14). Craniosynostosis is classified into two main categories: "simple" (or unisutural) when only one suture is involved (Fig. 11), and "complex" (compound) when two or more sutures are involved. It is usually more severe when more than one suture closes too early. The occurrence of the various types of simple craniosynostosis is approximately as follows: sagittal $50-55 \%$, coronal $20-29 \%$, metopic $4-10 \%$, and lambdoid $2-4 \%$ (8).

Although the etiology of craniosynostosis is currently unknown, animal experiments and a recent interest in molecular biology point toward interplay between the dura mater and the underlying brain (14). The cranial suture fate is programmed by the dura derived paracrine signals. The dura 

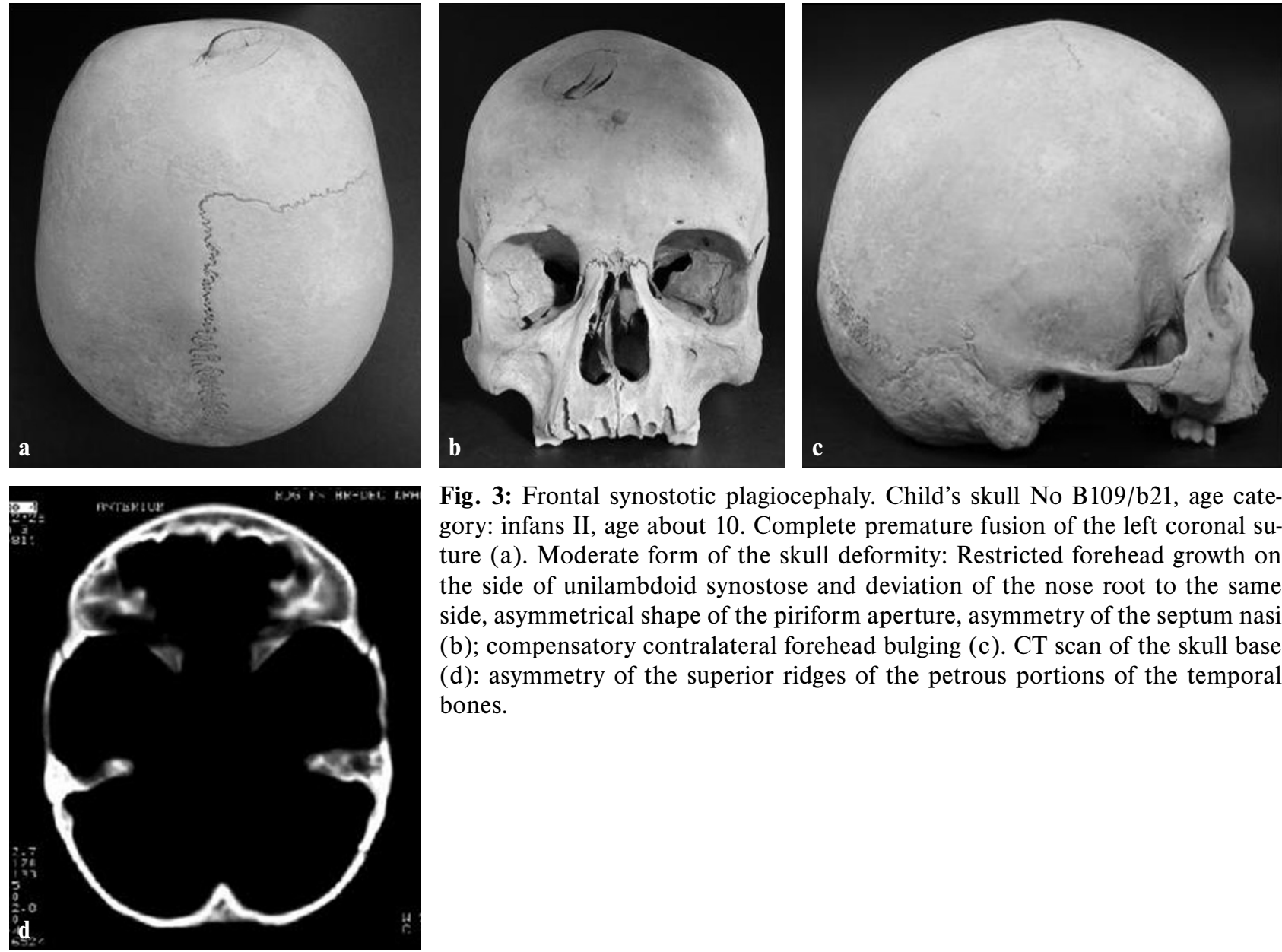

Fig. 3: Frontal synostotic plagiocephaly. Child's skull No B109/b21, age category: infans II, age about 10 . Complete premature fusion of the left coronal suture (a). Moderate form of the skull deformity: Restricted forehead growth on the side of unilambdoid synostose and deviation of the nose root to the same side, asymmetrical shape of the piriform aperture, asymmetry of the septum nasi (b); compensatory contralateral forehead bulging (c). CT scan of the skull base (d): asymmetry of the superior ridges of the petrous portions of the temporal bones.
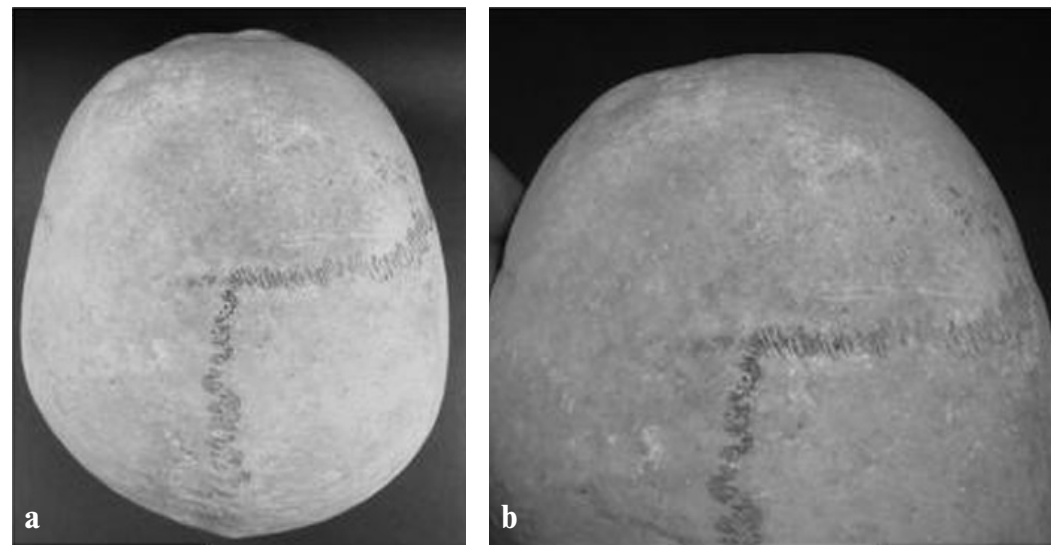

Fig. 4: Frontal synostotic plagiocephaly. Skull No. B124, adult male, age category: adultus II. Vertex view of the skull $(\mathrm{a}, \mathrm{b})$ shows premature synostosis of the left coronal suture except the short bregmatic part (the right coronal suture is patent). Moderate form of the skull deformity: asymmetry of the calvaria with ipsilateral frontal flattening (a-c), remarkable deviation of the nose root towards fused suture, deviation of the nasal bones, and asymmetry of the piriform aperture (c).

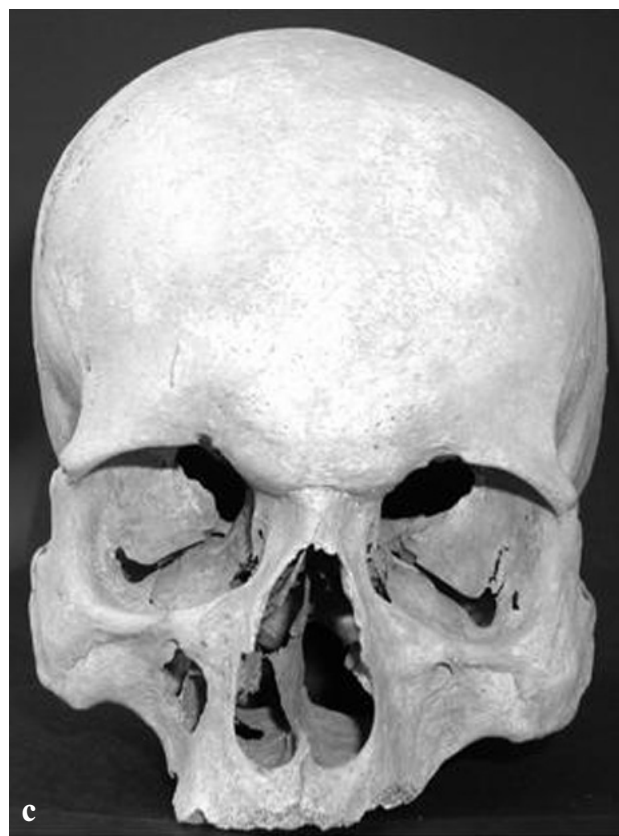



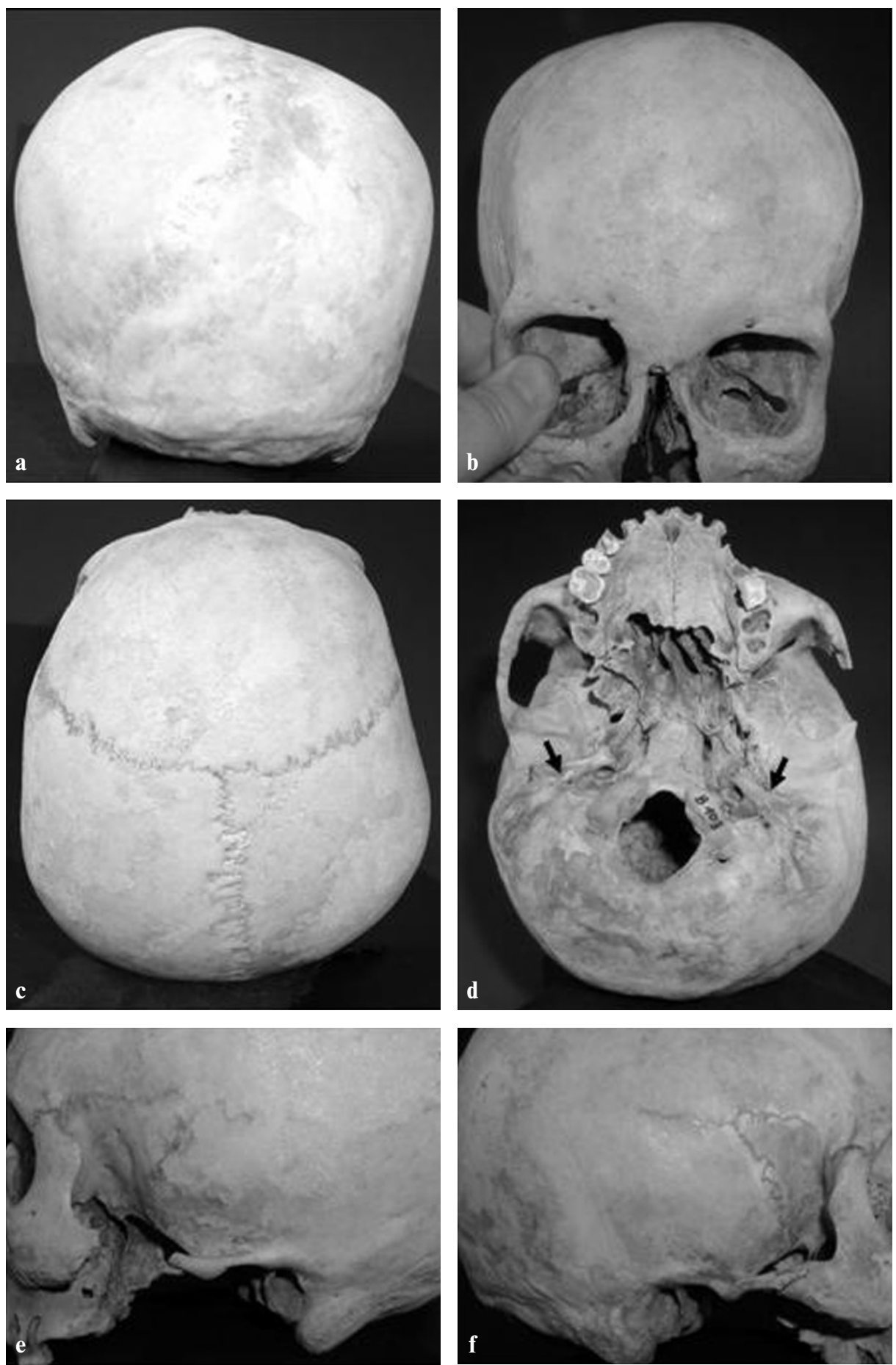

Fig. 5: Synostotic plagiocephaly associated with multiple premature sutural fusions. Skull No B103, adult male, age category: adultus II. Premature fusion of the right lambdoid suture (a), bilateral symmetrical fusion of the occipitomastoid sutures $(\mathrm{d}, \mathrm{e}, \mathrm{f})$, bilateral partial and asymmetrical fusion of the squamous suture (e,f). Parietooccipital flattening at the side of oblitered lambdoid suture (a-d). Asymmetrical course of the sagittal suture (c) with deviation towards the affected side. Scoliosis of the external cranial base, asymmetrical position of the external acoustic meatus (d, arrows). Asymmetry of temporal fossae (e,f): on the right side, the surface of the greater wing of the sphenoid bone is shorter. Remarkable face asymmetry: asymmetrical shape of the orbits, deviation of the nose root to the side of the lambdoid synostose, asymmetrical shape of the piriform aperture (b). 

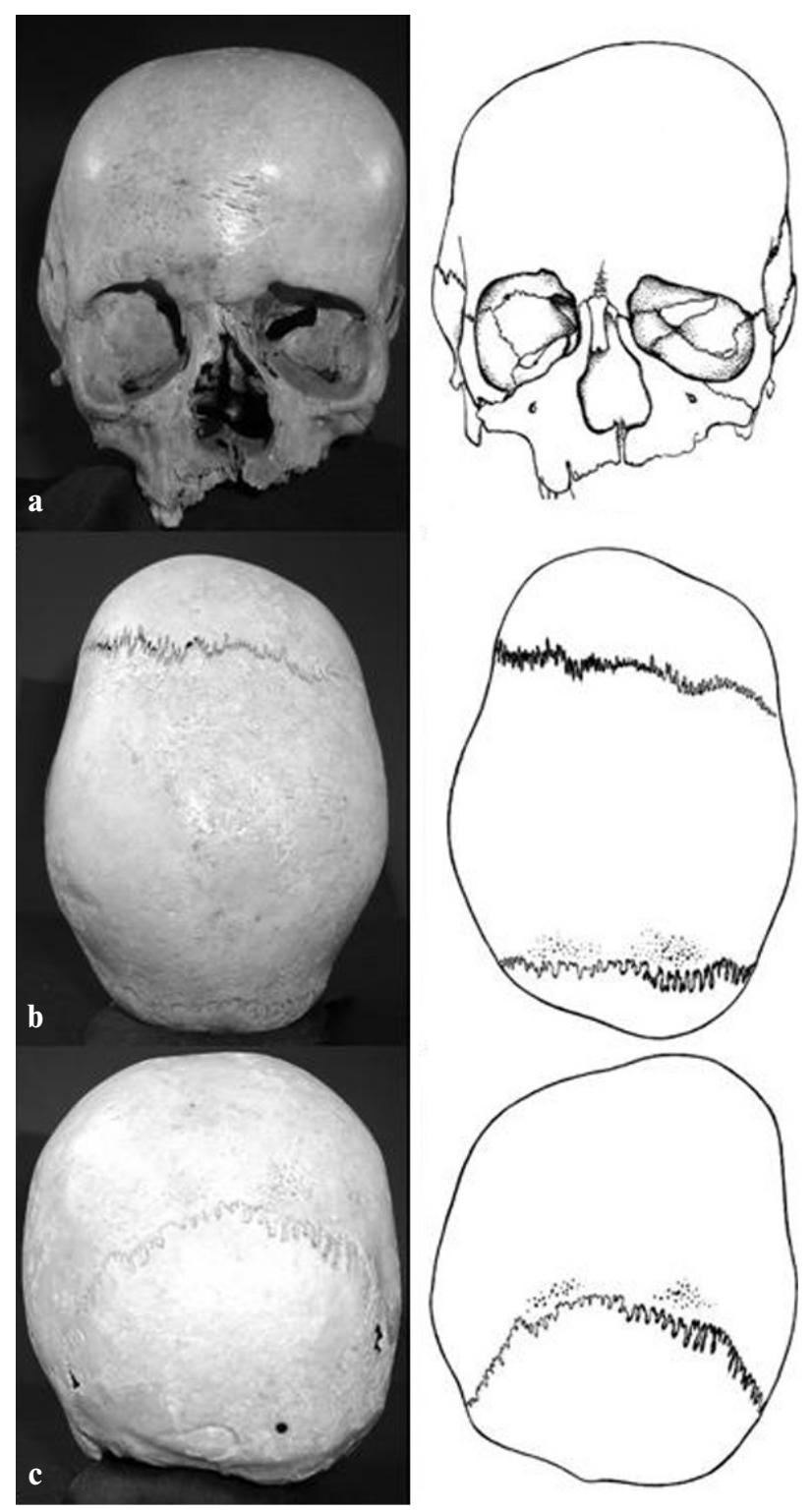

A
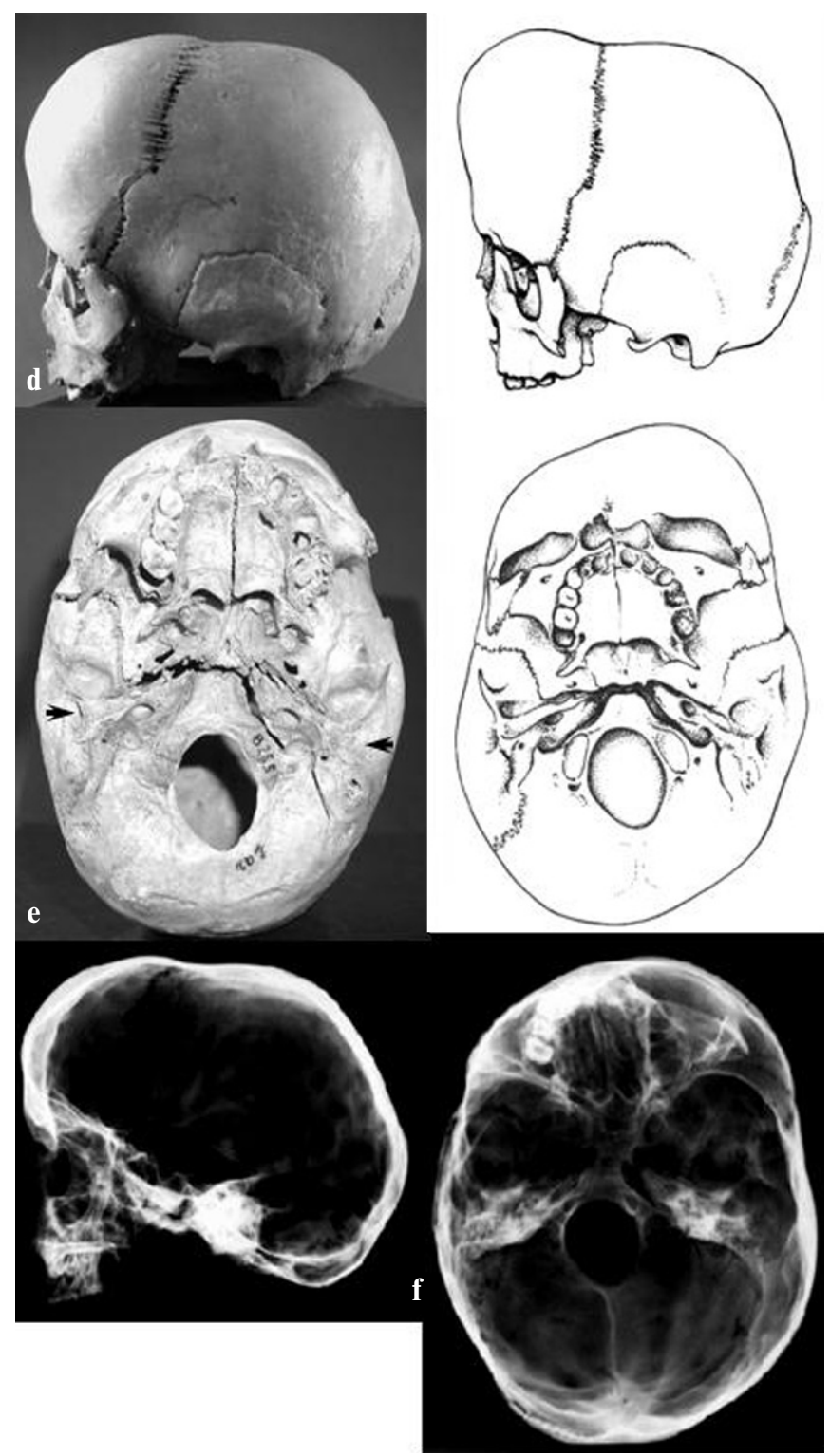

B

Fig. 6 A,B: Complex craniosynostosis with severe skull deformity: combination of the synostotic plagiocephaly with scaphocephaly Child's skull No B255/b92, age category: infans I, age about 5. Multiple premature suture synostosis: Partial obliteration of the right side coronal suture $(\mathrm{A} / \mathrm{b})$; complete obliteration of the sagittal suture (A/a), the left side sphenoparietal suture $(B / d)$ and occipitomastoid suture $(B / d, e)$; obliteration of the posterior part of the left side squamous suture (B/d). Asymmetrical deformity: Frontal flattening (A/a,b, B/e) and occipital bossing (B/e) on the side of fused coronal suture, compensatory frontal bossing on the opposite side $(\mathrm{A} / \mathrm{a}, \mathrm{b}, \mathrm{B} / \mathrm{d}, \mathrm{e})$, occipital flattening on the side of oblitered occipitomastoid and squamous sutures $(\mathrm{A} / \mathrm{c})$, asymmetry of the external acoustic meatus (B/e-arrows), asymmetrical shape of the foramen magnum $(\mathrm{B} / \mathrm{e})$; remarkably asymmetrical orbits - on the side of coronal synostosis, the orbit is enlarged and its upper margin is deviated upward (A/a); deviation of the nose root to the side of coronal fusion, asymmetry of the pirifom aperture (A/a). Scaphocephaly: hyperdolichocephaly $(\mathrm{A} / \mathrm{b})$, cephalic index 74 . Radiograph (B/f): long and narow skull, asymmetry of the skull base. Distinctive impressiones digitatae are suspect from intracranial hypertension. 

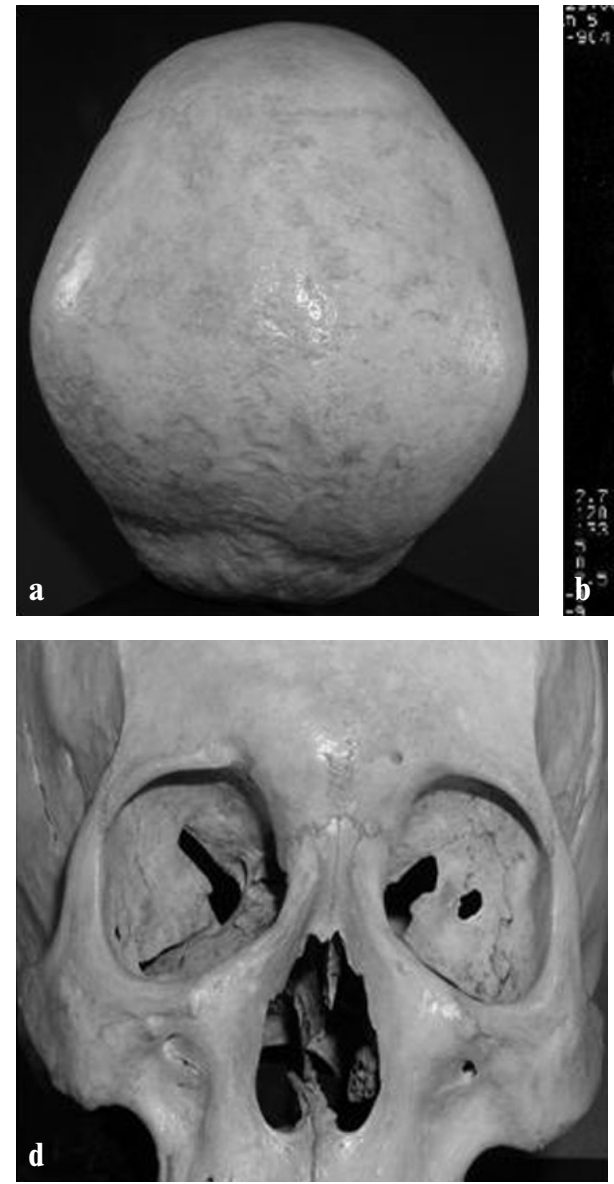
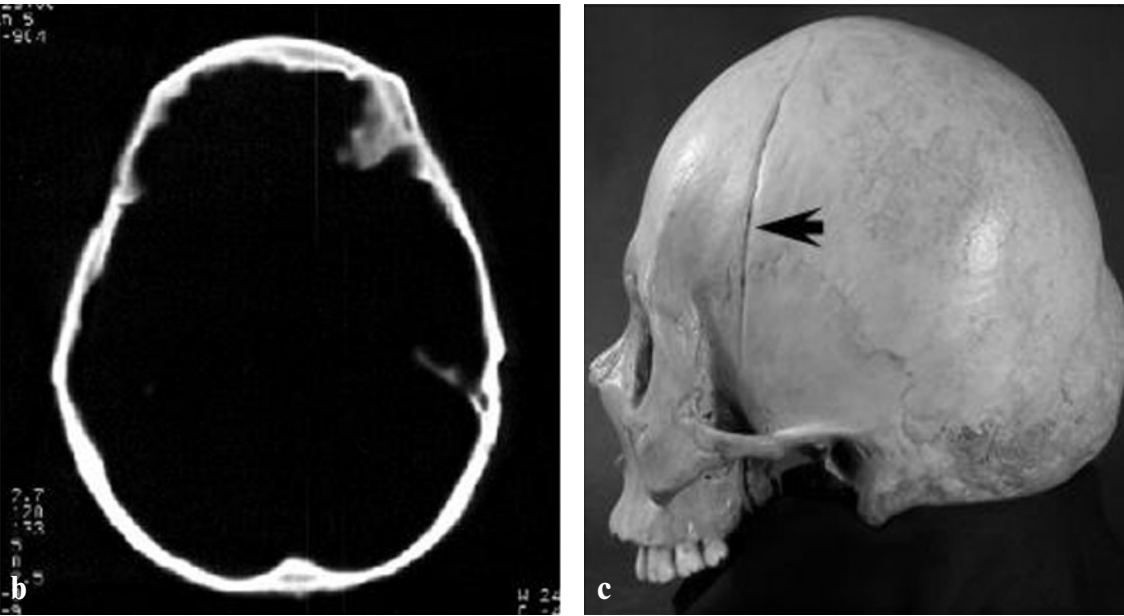

Fig. 7: Complex craniosynostosis - combination of the frontal synostotic plagiocephaly and brachycephaly. Skull No B666, adult individual (male?), age category: adultus I, age about 20 years. Multiple premature suture obliteration: asymmetrical fusion of both coronal sutures (complete obliteration on the left side, partial obliteration on the right side), asymmetrical obliteration of spheno-parietal and spheno-frontal sutures, bilateral symmetrical obliteration of lambdoid sutures. Well-healed war cutting wound on the left side of neurocranium mimics the coronal suture (c, arrow). Skull asymmetry: left side frontal flattening and the opposite side parietooccipital compensatory bossing (a), asymmetrical shape of the orbits, nose root deviation to the left side (the side of complete obliteration of the coronal suture) (d). The CT scan (b): Asymmetry of the internal skull base, predominantly of the anterior cerebral fossa. Brachycephaly: antero-posterior shortening of the skull, cephalic index 100,6.
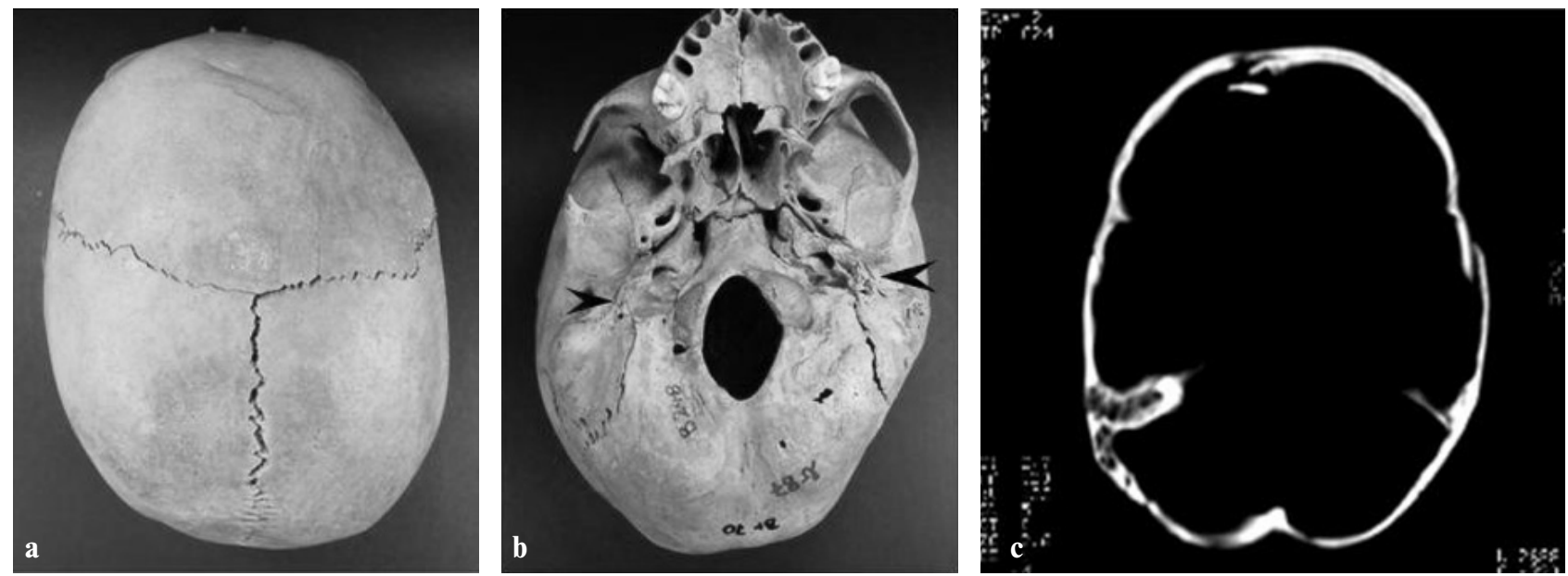

Fig. 8: Occipital positional plagiocephaly. Skull No B248/b87, age category: infans I, age about 6. Typical "parallelogram" head shape in vertex view (a), remarkable flattening of the left parietooccipital region (a,b), asymmetry of the external skull base with asymmetrical shape of foramen magnum (b). Asymmetrical position of external acoustic meatus - on the side of flattened occiput, meatus is positioned further forward (b, arrows). The CT scan (c) reveals asymmetry of the internal skull base, predominantly its posterior cranial fossa. 

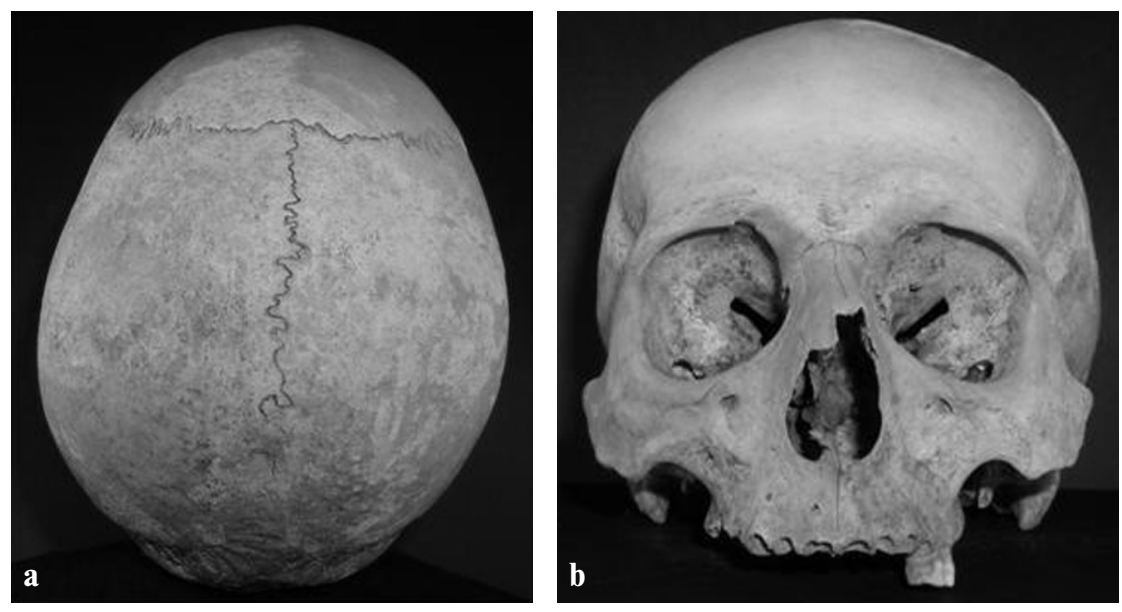

Fig. 9: Occipital positional plagiocephaly. Skull No B120, adult male, age category: adultus II. Parietoocipital skull flattening on the right side and ipsilateral compensatory frontal skull bossing. "Paralleologram" skull shape (a). Midline position of the nose root, deviation of the ossa nasalia to the left side (b).
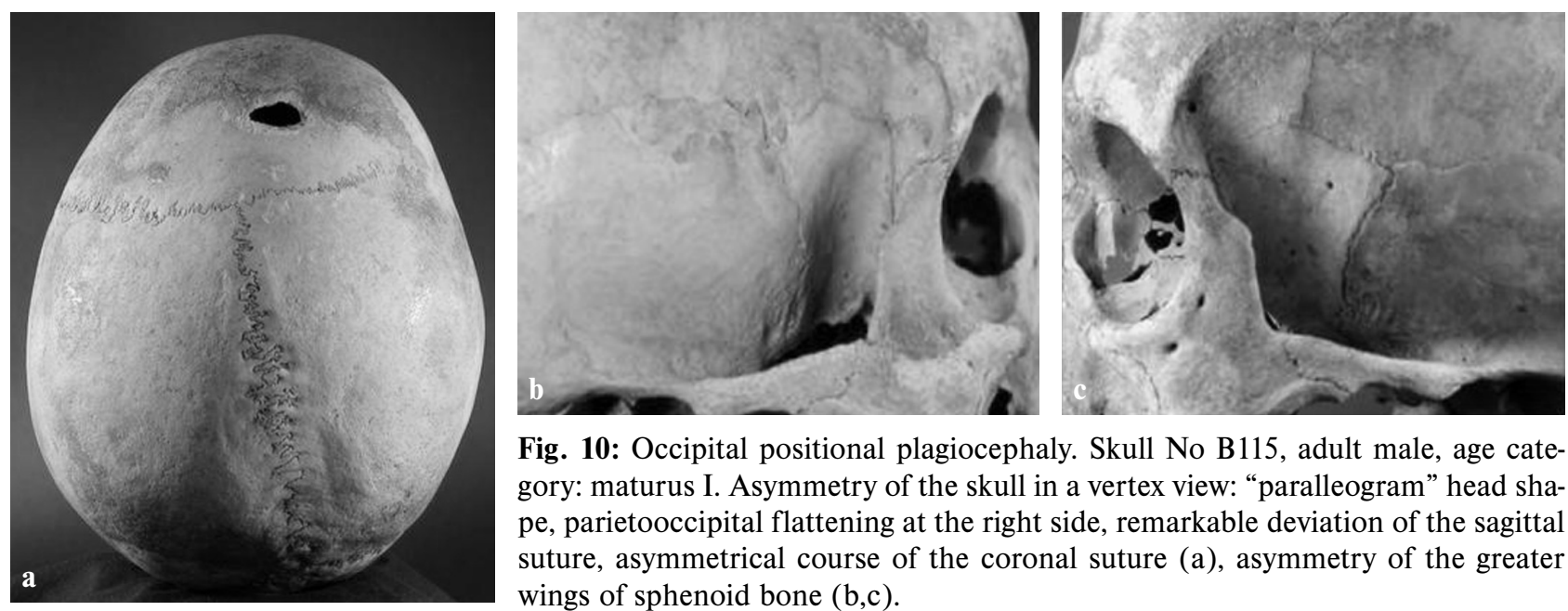

Fig. 10: Occipital positional plagiocephaly. Skull No B115, adult male, age category: maturus I. Asymmetry of the skull in a vertex view: "paralleogram" head shape, parietooccipital flattening at the right side, remarkable deviation of the sagittal suture, asymmetrical course of the coronal suture (a), asymmetry of the greater wings of sphenoid bone $(b, c)$.

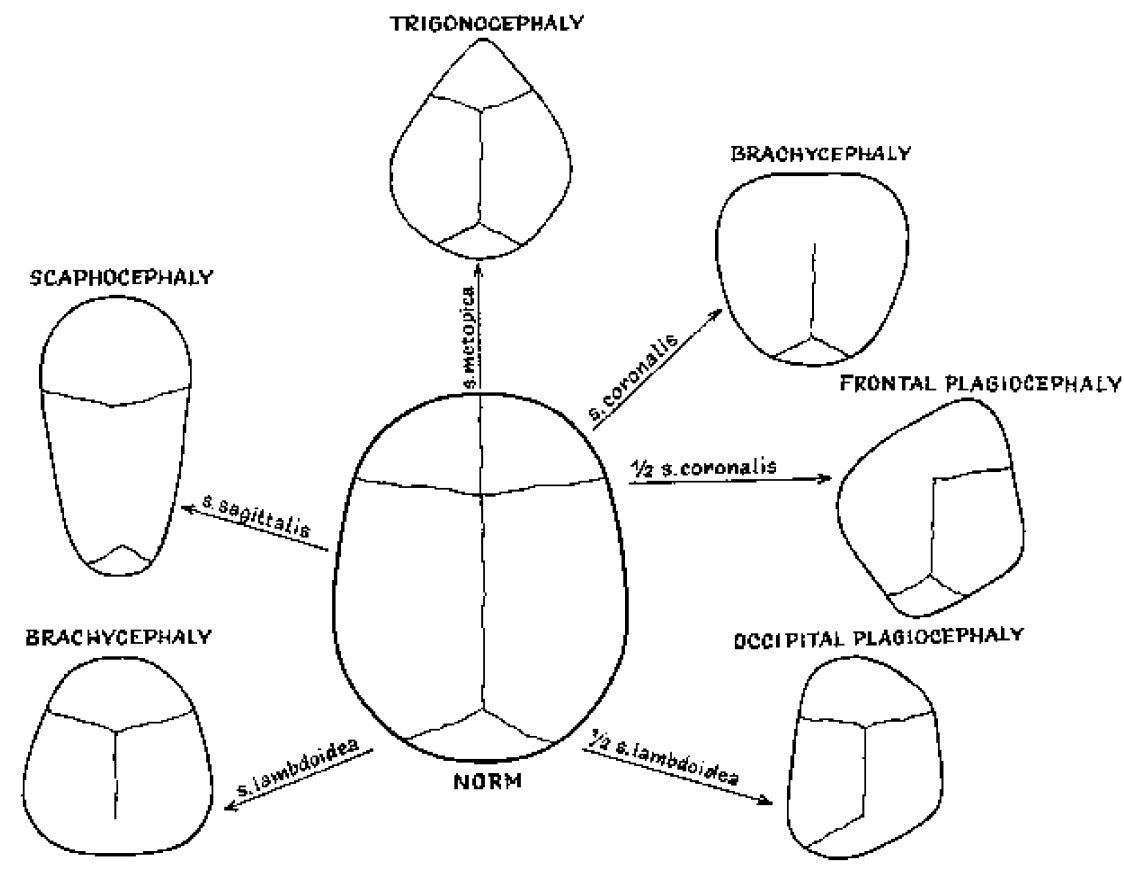

Fig. 11: Schematic drawing of simplex craniosynostosis: typical deformities of the skull. 
acts as a regionally specialized endogenous tissue engineering and provides the osteogenic factores (e.g. fibroblast growth factors). These factors regulate fetal osteogenic growth and possibly influence fetal suture patency (20). Mutations in the gene coding for fibroblast growth factors cause some syndromes with craniosynostosis (2).

In the contemporaneous population, craniosynostosis has been reported to occur approximately once per 2,000 live births (8). Unicoronal craniosynostosis - scarce form of craniosynostosis - happens in approximately one out of every 2,500 live birth (2), rare unilambdoid craniosynostosis happens in approximately three out of every 100,000 births (6). In contradistinction to recent clinical studies, in Broumov historical populations dating to the $13^{\text {th }}-18^{\text {th }}$ centuries, the incidency of synostotic plagiocephaly was rather high $(1.74 \%)$ : unicoronal craniosynostosis was present in $0.27 \%$ skulls, unilambdoid craniosynostosis in $0.13 \%$ skulls, synostotic plagiocephaly with asymmetrical fusions of some skull sutures in $0.94 \%$ skulls, and combination of synostotic plagiocephaly with another form of synostotic skull deformity in $0.40 \%$ skulls. Kabbani and Raghuveer (8) assume that the true incidence of craniosynostosis in population is higher then clinical studies assert. The present report supports the assumption of these authors.

Positional plagiocephaly is the most common cause of plagiocephaly (15). It results from asymmetrical cranial growth without craniosynostosis. The practice of artificial skull deformation by pressure to an infnant's head dates back to 2000 BC when several ancient civilizations have used head-molding to produce desired skull shape. Positional occipital plagiocephaly is caused by constant external pressure on the one side parieto-occipital region of the developing skull (3). Risk factors associated with the positional head deformity are prolonged exposure to traditional "back" sleeping position, premature birth, congenital muscular torticollis, and intrauterine constraint (e. g. in multiple gestation or oligohydramnion) (13). Following the American Academy of Pediatrics recommendation (in 1992) that babies sleep in supine position to reduce the risk of Sudden Infant Death Syndrome, the incidency of deformational plagiocephaly has increased dramatically. Before 1992, the incidency was one of every 300 healthy born infants. Nowadays, the condition occurs in one of every 60 live birth (7). High positional plagiocephaly occurrence (12.48\%) in skulls of Broumov historical populations was probably pre- dominately caused by traditional back sleeping position of newborns and suckling infants in past centuries.

\section{Acknowledgement}

The work was partially supported by the Ministry of Education Grant Agency (Grant No. 2532/F3/02).

\section{References}

1. Aufderheide AC, Rodriguéz-Martín C. The Cambridge encyclopedia of human paleopathology. Cambridge University Press, 1998:478.

2. Cassileth L, Barlett SP, Glat PM, et al. Clinical characteristics of patients with unicoronal synostosis and mutation of fibroblast growth factor receptor 3: A preliminary study. Plast Reconstr Surg 2001;108:1849-54.

3. Collett B, Breiger D, King D, Cunnigham M, Speltz M. Neurodevelopmental implications of "deformational" plagiocephaly. J Dev Behav Pediatr 2005;26: 379-89.

4. Currarino G. Premature closure of the frontozygomatic suture: Unusual frontoorbital dysplasia mimicking unilateral coronal synostosis. AJNR Am J Neuroradiol 1985;6:643.

5. Farkas LG, Forrest CR. Changes in antropometric values of paired craniofacial measurments of patients with right coronal synostosis. Ann Plast Surg 2006 56:427-30.

6. Goodrich JT, Argamaso R. Lambdoid stenosis (posterior plagiocephaly) and craniofacial asymmetry: long-term outcomes. Chid's Nerv Syst 1996;12:720-6.

7. Hutchison BL, Hutchison LAD, Thompson J, Mitchel EA. Plagiocephaly and brachycephaly in the first two years of life: A prospective study. Pediatrics 2004;114:970-980.

8. Kabbani H, Raghuveer TS. Craniosynostosis. Am Fam Physician 2004;69: 2863-70.

9. Kelly KM, Littlefield TR, Pomatto JK, Manwaring KH, Beals SP. Cranial growth unrestricted during treatment of deformational plagiocephaly. Pediatr Neurosurg 1999:30:193-9.

10. Kreiborg S, Björg A. Craniofacial asymmetry of a dry skull with plagiocephaly. Euro J Orthodont 1981;3:195 -203.

11. Martinez-Large JF, Ruiz-Espejo AM, Gilabert A, Perez-Espejo MA, GuillenNavaro E. Positional skull deformities in children: skull deformation without synostosis. Child Nerv Syst 2006;22:368-74

12. Menard RM, David DJ. Unilateral lambdoid synostosis: Morphological characteristics. J Craniofac Surg 1998;9:240-6.

13. Morrison CS, Chariker M. Positional plagiocephaly: pathogenesis, diagnosis, and management. J Ky Med Assoc 2006;104:136-40.

14. Panchal J, Uttchin V. Management of craniosynostosis. Plast Reconstr Surg 2003;111:2032-49

15. Petsch WK, Keefer CH, LaBrie RA, Mulliken JB. Incidence of cranial asymmetry in healthy newbors. Pediatrics 2002;110:72-86.

16. Regelsberger J, Helmke K. Positional plagiocephaly and true craniosynostosis reliable diagnosis by high-frequency sonography. Ultraschall Med 2005;26:1055.

17. Rogers G, Proctor M, Mulliken J. Unilateral fusion of the frontosphenoidal suture: A rare cause of synostotic frontal plagiocephaly. Plast Reconstr Surg 2002; 110:1011-21.

18. Sakurai A, Hirabayashi S, Sugawara Y, Harii K. Skeletal analysis of craniofacial asymmetries in plagiocephaly (unilateral coronal synostosis). Scand J Plast Reconstr Hand Surg 1998;32:81-9.

19. Vastardis H, Mulliken JB, Glowacki J. Unilateral coronal synostosis: A histomorphometric study. Cleft Palate Craniofac J 2003;41:439-46.

20. Warren SM, Longaker MT. The pathogenesis of craniosynostosis in the fetus. Yonsei Med J 2001;42:646-59.

21. Wood R, Shell CH. Craniosynostosis and deformational plagiocephaly: How to differentiate the conditions. Pediatr Perspective 2005;14:1-6.

Submitted November 2006. Accepted December 2006.

Corresponding author:

MUDr. Blanka Pospíšilová, CSc., Charles University in Prague, Faculty of Medicine in Hradec Králové, Department of Anatomy, Šimkova 870, 50038 Hradec Králové, Czech Republic, e-mail: pospisil@lfhk.cuni.cz 